\title{
Joint Meeting
}

The European Society for Clinical Hemorheology and Microcirculation

The International Society for Clinical Hemorheology

The International Society of Biorheology

Krakow, Poland

July 2-6, 2018

\section{Scientific Program}

Monday, July 2nd

\subsection{0-18.00 Registration \\ 18.00-19.30 Opening Ceremony}

20.00-21.30 Welcome Reception

Tuesday, July 3rd

9.00-10.00 ESCHM Plenary Lecture (L1)

Chair: Jean-Frédéric Brun

Lecture: Philippe Connes

Blood rheology: From exercise responses to sickle cell disease

pathophysiology

10.00-10.30 Coffee Break

10.30-12.00 Symposia S1-S3/Free Communications O1-O2

S1: VESSELS AND HEMORHEOLOGY

Chairs: Kalman Toth and Norbert Nemeth

S1-1 Hemorheological parameters and mortality in critically ill patients Beata Csiszar, Kinga Totsimon, Peter Kenyeres, Kalman Toth, Zsolt Marton

S1-2 Leukocyte antisedimentation rate (LAR) and pituitary adenylate cyclase-activated polypeptid (PACAP) in polytrauma and burn victims. A preliminary study Csaba Loibl, Csaba Csontos, Livia Szelig, Lajos Bogar, Patricia Kovacs, Andrea Pankaczi, Szilard Rendeki, Martin Rozanovic, Marianna Matancic, Timea Nemeth, Beata Lelesz, Jozsef Nemeth, Attila Miseta, Dora Reglodi, Andrea Tamas

S1-3 Do AB0 and Rh blood groups influence hemorheological parameters in vascular patients? 
Katalin Koltai, Dóra Endrei, Gábor Késmárky, Katalin Biró, Zsolt Márton Pécs, Gergely Fehér, Dávid Kovács, Imre Boncz, Antal Tibold, Kálmán Tóth

S1-4 Applications of finite element analysis in clinical hemorheology

Peter Varga, Sz. Javor, G. Jancso, A. Gedei, P Maroti, G. Balazs University of Debrecen Hungary

S1-5 Effects of ischemia-reperfusion and various surgical preconditioning maneuvers on micro-rheological and microcirculatory parameters

Norbert Nemeth, Gabor Varga, Balazs Szabo, Csaba Korei, Bela Turchanyi, Katalin Peto

S1-6 Renal ischemia-reperfusion-induced micro-rheological and microcirculatory alterations and their influenceability by remote organ ischemic preconditioning Gabor Varga, Kitti Nagy, Noemi Pal, Gabor Nadubinszky, Balazs Szabo, Bence Tanczos, Viktoria Somogyi, Adam Deak, Katalin Peto, Norbert Nemeth

S2: PLATELET ADHESION

Chairs: Shinya Goto and Terumitsu Hasebe

S2-1 Biologically validated model of platelet adhesion under blood flow conditions Shinya Goto

S2-2 Glycoprotein distribution of surface-induced platelet activation on medical materials by electron microscopy technology

Masamitsu Nakayama, Terumitsu Hasebe, Shunto Maegawa, Kenta Bito, Tomohiro Matsumoto, Tetsuya Suzuki

S2-3 Hemorheological effects of mechanical stress on whole blood of patients with prosthetic heart valve failure

Toru Maruyama, Chiharu Yoshida, Kei Irie, Shohei Moriyama, Taku Yokoyama, Mitsuhiro Fukata, Takeshi Arita, Keita Odashiro, Koichi Akashi

S2-4 Platelet adhesion studies of implantable long-term use Fontan pump biomaterials Bryan Good, Clare McHugh, Keefe Manning, William Weiss, Chris Siedlecki

S2-5: Development of hemocompatible materials for blood contacting devices by physical and chemical surface modification

Terumitsu Hasebe, Masamitsu Nakayama, Shunto Maegawa, Kenta Bito, Tomihiro Matsumoto, Tetsuya Suzuki

S3: $\quad$ ADVANCES IN HEMORHEOLOGICAL MEASUREMENTS-1

Chairs: Sehyun Shin and Sung Yang

S3-1 Holotomography techniques for imaging 3D label-free imaging of cells and tissues

Yong Keun Park

S3-2 A microfluidic device for simultaneous measurement of blood viscosity, hematocrit, and deformability

Byung Jun Kim, Sung Yang

S3-3 Deformability measurement of continuous soft particles by lattice Boltzmann method and its applications to rheological flow characteristics

Joon-Sang Lee 
S3-4 A microfluidic platelet assaying device for function test and antiplatelet response test

Sehyun Shin

O1: CELLULAR RHEOLOGY AND BIOPHYSICS

Chair: Peter Butler

O1-1 Albumin solder covalently bound to a biodegradable polymer membrane: New approach to improve binding strength in laser tissue soldering

Andrea Nies, Bernhard Hiebl

O1-2 Circumferential alignment of smooth muscle cells in micro-tube environment Yang Jin, Linhong Deng

O1-3 Subhaemolytic mechanical trauma increases RBC aggregation by altering cell electrochemistry

Antony McNamee, Geoff Tansley, Michael Simmonds

O1-4 Subhaemolytic mechanical damage alters erythrocyte behavior in subsequent low-shear flows

Antony McNamee, Geoff Tansley, Michael Simmonds

O1-5 Ultrafast imaging of cell elasticity with optical microelastography

Guy Cloutier, Grasland-Mongrain, Ali Zorgani, Shoma Nakagawa, Simon Bernard, Lia Gomes Paim, Greg FitzHarris, Stefan Catheline

O1-6 The effects of substrate stiffness on HUVEC adhesion with THP-1 cells and molecules associated with adhesion

Yan Wenhua Zhang Tian, Zhang Kang, Qiu Juhui, Wang Guixue

O2: CLINICAL HEMORHEOLOGY

Chair: Jean-Frédéric Brun

O2-1 Pilot clinical study of quantitative ultrasound spectroscopy measurements of erythrocyte aggregation within superficial veins of 50 volunteers

Guy Cloutier, Boris Chayer, Louise Allard, Julian Garcia-Duitama

O2-2 Rapid clinical assessment of the sublingual microcirculation - Visual scoring using microVAS in comparison to standard semi-automated analysis

Joel Sardinha, Christian Lehmann

O2-3 L-cysteine improves blood fluidity that has been impaired by acetaldehyde Ippo Otoyama, Tatsushi Kimura, Hironobu Hamada, Kiyokazu Sekikawa, Michinori Kamikawa, Teruki Kajiwara, Fumiya Aizawa, Yoshinobu Sato, Haruchi Namba

O2-4 Hemorheological studies in a group of patients with Waldenström's macroglobulinemia

Anna Marcinkowska-Gapińska, Piotr Kowal, Włodzimierz Liebert

O2-5 Adora2b receptor activation mediates flap protection from ischemia/reperfusion injury

Pinar Ulker, Ozlenen Ozkan, Matteo Amoroso, Mutay Aslan, Filiz Ozcan, Ibrahim

Bassorgun, Omer Ozkan

O2-6 Purinergic regulation of erythrocyte enzyme activity 
Pinar Ulker, Nur Özen, Günel Abdullayeva, Sadi Köksoy, Nazmi Yaraş, Filiz Basrali

13.00-14.00 Poiseuille Gold Medal Award (L2)

Ceremony and Lecture

Laudatio: Herbert H Lipowsky

Lecture: Axel R Pries

Microvascular hemodynamics: System properties

\subsection{5-15.45 Symposia S4-S7/Free Communications O3}

\section{S4: GLYCOCALYX - ITS STRUCTURE AND FUNCTION}

Chairs: John Tarbell and Hans Vink

S4-1 Multilayer structures of the endothelial glycocalyx: barrier functions versus red cell hemodynamics

FitzRoy Curry

S4-2 Endothelial Surface Glycocalyx (ESG) components and ultra-structures revealed by Stochastic Optical Reconstruction Microscopy (STORM)

Jie Fan, Yi Sun, Yifan Xia, John Tarbell, Bingmei Fu

S4-3 In vivo studies of the enzymatic degradation and structure of the endothelial glycocalyx

Herbert Lipowsky

S4-4 The endothelial glycocalyx and control of microvascular flow and perfused capillary density

Hans Vink

S5: NOVEL MECHANISMS REGULATING BLOOD CELL RHEOLOGY

Chairs: Brian Cooke and Tamas Alexy

S5-1 Interaction of mesenchymal stem cells with platelets: Aid to targeting to tissue or thrombotic risk?

Lozan Sheriff, Asma Alanazi, Lewis Ward, Julie Rayes, Mohammed Alassiri, Steve Watson, Gerard Nash

S5-2 Malaria and babesiosis: Same rheopathobiology but different molecular mechanisms

Brian Cooke

S5-3 Form and function: erythrocyte responses to supra-physiological shears and circulatory support

Michael Simmonds

S5-4 Blood rheology, arterial stiffness, and clinical complications in diabetic patients with and without sickle-cell trait

Sarah Skinner, Mor Diaw, Maïmouna Ndour Mbaye, Brigitte Ranque, Philomène Lopez, Malick Ndour, Fatou Gueye, Demba Diedhiou, Djiby Sow, Saliou Diop, Abdoulaye Samb, Vincent Pialoux, Philippe Connes 
S5-5 The importance of hemorheology in the design of continuous flow left ventricular assist devices

Tamas Alexy

S6: $\quad$ ADVANCES IN HEMORHEOLOGICAL MEASUREMENTS-2

Chairs: Sehyun Shin and Sung Yang

S6-1 Optical study of red blood cells interactions in vitro mediated by different plasma components

Alexander Priezzhev, Alexey Semenov, Andrei Lugovtsov, Kisung Lee, Christian Wagner

S6-2 Effect of integrin glycoproteins inhibition on specific adsorption of cells adhesion macromolecules on red blood cell membrane: A microrheologic study

Alexey Semenov, Andrei Lugovtsov, Kisung Lee, Alexei Myravyev, Sehyu Shin, Evgeny Shirshin, Alexander Priezzhev

S6-3 Electrochemical impedance spectroscopy of blood for blood aggregation, sedimentation, and hematocrit

Alexander Zhbanov, Sung Yang

S6-4 Comparison of critical shear stress in RheoScan and adhesion force between RBCs measured in optical tweezer

Sehyun Shin, Hoyoon Lee, Kisung Lee, Alexander Priezzhev

S7: HEMORHEOLOGY AND BLOOD COAGULATION

Chairs: Ursula Windberger and Resia Pretorius

S7-1 Stress sweep tests on whole blood clots

Ursula Windberger

S7-2 The novel discovery of amyloid formation in fibrin(open) and how it affects hemorheology and blood coagulation

Etheresia Pretorius

S7-3 Multiscale mechanics of fibrin networks

Cristina Martinez-Torres

S7-4 Study of blood clotting mechanism by rheological and electrorheological methods Nadia Antonova, Ivan Ivanov

S7-5 Influence of polymeric nanoparticles on the kinetics of coagulation of conserved blood

Nadya Todorova, Nadia Antonova

S7-6 What are conditions defining blood clot properties in some disorders

Eugene Roitman, Alla Shabalina, Marine Tanashyan, Irina Kolesnikova

O3: $\quad$ ENDOTHELIAL FUNCTION AND SHEAR STRESS

Chairs: Markos Klonizakis and Guixue Wang

O3-1 Arrangement and morphology of endothelial cells under the mechanical microenvironment changes after vascular stent implantation

Tieying Yin, Yuzhen Ren, Ruolin Du, Yuhua Huang, Yazhou Wang, Guixue Wang 
O3-2 Blood Flow Regulates Zebrafish CVP Angiogenesis by Inducing ERK5 Signaling Guixue Wang

O3-3 The role of Id1 in oscillatory shear stress-mediated endothelial lipid uptake Kang Zhang, Yidan Chen, Guixue Wang

O3-4 Effect of DNA methyltransferase 1 in oscillatory shear stress-induced atherosclerotic vulnerable plaque formation

Lu Huang, Desha Luo, Yuanhang Zhou, Kang Zhang, Juhui Qiu, Guixue Wang

O3-5 The influence of hemodynamic changes on proliferation and adhesion of endothelial progenitor cells

Jinxuan Wang, Li Xiao, Daming Sun, Yiming Zheng, Tieying Yin, Guixue Wang

O3-6 Short term effects of the Mediterranean Diet in human microvascular function comparison between older and younger healthy, sedentary adults Yingshan Liu, Marianne Milner, Markos Klonizakis

\subsection{5-17.45 Symposia S8-S12}

\section{S8: $\quad$ GLYCOCALYX - ITS DIVERSITY}

Chair: Herbert Lipowsky

S8-1 Surface glycocalyx mediates tumor cell metastasis

Henry Qazi, Heriberto Moran, Limary Cancel, Mariya Mayer, Lance Munn, John Tarbell

S8-2 Visualization of heparan sulfate proteoglycans in the glycocalyx and the perivascular space of 3-dimensional perfusable microvascular networks in microfluidic devices

Sebastian Beyer, Anna Blocki, Roger D. Kamm

S8-3 Integrin-mediated adhesion is lipid bilayer and glycocalyx dependent

Seoyoung Son, Joseph Moroney, Peter Butler

S8-4 Coupled dynamics of blood flow and endothelial glycocalyx: A large-scale molecular dynamics study

Xi Zhuo Jiang, Kai H. Luo, Yiannis Ventikos

S9: MOLECULAR AND MECHANICAL MARKERS OF VARIOUS PATHOLOGIES

Chair: Małgorzata Lekka

S9-1 Early stage of essential hypertension monitoring

Kvetoslava Burda, Magdalena Kaczmarska, Maria Fornal, Franz Messerli, Jozef Korecki, Tomasz Grodzicki

S9-2 Label-free methods in diagnostics and prognostics of malignant melanoma Tomasz Kobiela

S9-3 Advanced vibrational imaging techniques to aid clinical research Tomasz P. Wrobel, Paulina Koziol, Natalia Piergies, Ewa Pieta, Czeslawa Paluszkiewicz, Maria Fornal, Tomasz Grodzicki, Wojciech Kwiatek

S9-4 Effect of dietary carotenoids on erythrocytes from diabetic patients: A spectroscopic study 
Joanna Fiedor, Mateusz Przetocki, Grzegorz Gajos, Józef Korecki, Kvetoslav Burda

S10: MiDAS MICROCIRCULATION MEETING (3M)

Chairs: Christian Lehmann and Vladimir Cerny

S10-1 Dynamic Contrast Enhanced Ultrasound (CEUS) of tissue transplants

Ernst Michael Jung, Sebastian Geis, Andreas Kehrer, Philipp Edmund Lamby, Lukas Prantl

S10-2 Assessment of glycocalyx

Vladimir Cerny

S10-3 Automated vs. visual video analyses - where is the future?

Christian Lehmann

S10-4 Is sodium a link between endothelial glycocalyx and microcirculation?

David Astapenko, Vladimir Cerny

S11: BEYOND RED CELL STIFFNESS

Chairs: Jean-Frédéric Brun and Carlota Saldanha

S11-1 RBC deformability: An exquisite homeostasis

Jean-Frédéric Brun, Emmanuelle Varlet-Marie

S11-2 Eryptosis or the death of a rigidified erythrocyte

Etheresia Pretorius

S11-3 Erythrocyte deformability under nitric oxide Influence

Carlota Saldanha, Ana Silva-Herdade

S11-4 The sickle cell: Far more than a rigid erythrocyte Philippe Connes, Elie Nader, Nicolas Guillot, Romain Fort, Berenike Möckesch, Nathalie Lemonne, Sophie Antoine-Jonville, Céline Renoux, Philippe Joly, Vincent Pialoux, Marie-Dominique Hardy-Dessources, Marc Romana

S11-5 Signaling pathways in regulation of RBC microrheological properties by catecholamines

Irina Tikhomirova, Alexei Myravyov, Elena Petrochenko

S11-6 Complete dynamics of erythrocytes in shear flow: The story behind the term of deformability

Simon Mendez, Luca Lanotte, Johannes Mauer, Franck Nicoud, Gerhard Gompper, Dmitry Fedosov, Manouk Abkarian

S12: MACRO AND MICRO HEMORHEOLOGY IN VITRO AND IN VIVO Chairs: Michael Simmonds and Jon Detterich

S12-1 The "tipping point" of mechanical stress on erythrocyte biology Michael Simmonds

S12-2 Testing the sensitivity of red cell fragmentation and deformability measurements for shear-mediated mechanical damage

Özlem Yalcin, Ali Cenk Aksu, Elif Ugurel, Selcuk Surucu 
S12-3 Discussion about high shear stress induced erythrocyte's damage and lysis Interpretation of hemolysis in cardiovascular devices based on our visualized erythrocytes' behaviors

Nobuo Watanabe, Takahiro Shimada, Nao Ikeda, Kousuke Igarashi

S12-4 Mechanical sensitivity of blood in sickle patients on chronic blood transfusion - understanding erythrocyte exposure to chronic physiologic shear vs. chronic supra-physiologic but sub-hemolytic shear stress

Jon Detterich, Silvie Siriany, Derek Ponce, Michael Simmonds

S12-5 Drag-reducing polymer effects on macro- and microcirculation Marina Kameneva

Wednesday, July 4

9.00-10.00 ISB Plenary Lecture (L3)

Chair: Peter Butler

Lecture: Frank J.Gijsen

Biomechanics and atherosclerotic plaques progression

\subsection{0-12.00 Symposia S13-S15/Free Communications O4-O5}

\section{S13: MICROCIRCULATION OF INNER ORGANS}

Chairs: Ernst Michael Jung and Pamela Zengel

S13-1 Critical analysis of CEUS examinations of the liver in an interdisciplinary ultrasound department

Franz Josef Putz, Anna Erlmeier, Niklas Verloh, Bernhard Banas, Christian Stroszczynski, Ernst Michael Jung

S13-2 VTIQ and VTQ in combination with B-mode and color Doppler ultrasound improve classification of salivary gland tumors, especially for inexperienced physician

Pamela Zengel, Florian Notter, Dirk Andre Clevert

S13-3 CEUS perfusion imaging after ablation treatment in patients with prostate cancer: First results

Isabel Wiesinger, Lukas Beyer, Philipp Wiggermann, Christian Stroszczynski, Ernst Michael Jung

S13-4 Contrast-enhanced ultrasound (CEUS) and gallbladder diseases - a retrospective monocenter analysis of imaging findings with histopathological correlation G. Negrão de Figueiredo, K. Mueller-Peltzer, P. Zengel, E. Gresser, J. Rübenthaler, D.A. Clevert, München

S13-6 New horizons for kidney imaging: Dynamic microvascularization in contrastenhanced ultrasound (CEUS)

Franz Josef Putz, Anna Erlmeier, Miriam Banas, Bernhard Banas, Ernst Michael Jung

S14: CELL MECHANICS AND CELL MECHANOBIOLOGY - 1

Chairs: Taiji Adachi and Yukiko Matsunaga 
S14-1 Effect of physical environment on cell migration using microchannel device Toshiro Ohashi, Mazlee Bin Mazalan, Ma Ming, Jennifer H. Shin

S14-2 Protein kinase $\mathrm{C} \alpha$ translocation in endothelial cells in response to mechanical stimulus

Susumu Kudo, Toshihiro Sera, Masataka Arai

S14-3 Hydrostatic pressure-induced DNA breaks in chondrocytes and its relationship with chromatin architecture

Koichiro Maki, Katsuko Furukawa, Takashi Ushida

S14-4 In situ, fluorescence lifetime-based measurements of cell membrane micromechanics

Seoyoung Son, Hari Muddana, Changjin Huang, Sulin Zhang, Peter Butler

S15: HEMODYNAMIC FUNCTIONALITY OF RED BLOOD CELLS IN BLOOD MICROCIRCULATION: EXPERIMENTS AND MODELING

Chairs: Saul Yedgar and Ming Dao

S15-1 Biomechanics of red cell diseases

Ming Dao

S15-2 Microvascular blood flow peculiarities in cancer Irina Tikhomirova, Yulia Malysheva, Nikolay Kislov, Mihail Ryabov

S15-3 Shape and dynamics of red blood cells in microvessels

Johannes Mauer, Felix Reichel, Jochen Guck, Gerhard Gompper, Dmitry Fedosov

S15-4 Hemodynamic functionality of transfused red blood cells in the microcirculation of blood recipients

Gregory Barshtein, Axel Pries, Neta Goldschmidt, Orly Zelig, Dan Arbell, Saul Yedgar

S15-5 Red blood cell aggregate flow characteristics in bifurcating microchannels Efstathios Kaliviotis, Joseph Sherwood, Stavroula Balabani

O4: RED BLOOD CELL DEFORMABILITY

Chairs: Edgar O'Rear and Philippe Connes

O4-1 Beta-estradiol and ethinylestradiol enhance RBC deformability dependent on their blood concentration

Paulo Farber, Teresa Freitas, Carlota Saldanha, Ana Silva-Herdade

O4-2 Dual mechanical characterization of red blood cells: Role of surface area, internal viscosity and membrane rigidity

Céline Renoux, Magali Faivre, Amel Bessaa, Philippe Joly, Philippe Connes

O4-3 Proteomic analysis of the role of adenylyl cyclase-cAMP pathway in red blood cell mechanical response

Özlem Yalcin, Elif Ugurel

O4-4 The oxygen scan: continuous measurement of red blood cell deformability with oxygen gradient ektacytometry to monitor disease severity and treatment effect in sickle cell disease 
Minke Rab, Brigitte van Oirschot, Tesy Merkx, Annet van Wesel, Sisto Hendriks, Jan de Zoeten, Osheiza Abdulmalik, Martin Safo, Birgitta Versluijs, Roger Schutgens, Gerard Pasterkamp, Eduard van Beers, Richard van Wijk

O4-5 Nitric oxide regulates human erythrocyte deformability through adjusting band phosphorylation status in hypoxia

Yajin Zhao, Xiang Wang

O4-6 Hypoxia: The best stimulator that increases shear-induced response of red blood cells

Elif Ugurel, Ali Cenk Aksu, Senol Piskin, Özlem Yalcin

O5: FLOW VISUALIZATION AND MODELING

Chairs: Sung Yang and Efstathios Kaliviotis

05-1 Velocity and erythrocyte aggregation characteristics for surface tension-driven flow of blood in rectangular microfluidic channels

Dimitris Pasias, Efstathios Kaliviotis

O5-2 A new approach of blood viscosity: Hemodynamic viscosity Tilly Alexandre

O5-3 Evaluation and comparison of haemodynamic parameters of vascular end-to side anastomoses

Balazs Gasz, Peter Varga, Peter Maroti, Gabor Jancso

O5-4 Similarities in erythrocyte senescence and microfluidic high shear environment Damage James Buerck, Dimitrios Papavassiliou, Trevor Snyder, David Schmidtke, Edgar O'Rear

O5-5 Investigation of bright collapsing ring by Lattice Boltzmann method Young Woo Kim, Chan Soo Min, Joon Sang Lee

13.00-14.00 ISCH Medal Award (L4)

Ceremony and Lecture

Laudatio: Kalman Toth

Lecture: Brian M. Cooke

The rheopathobiology of malaria and babesiosis

\subsection{5-15.45 Symposia S16-S18/Free Communications O6}

S16: SPECIAL SYMPOSIUM TO CELEBRATE THE CENTENNIAL OF DISTINGUISHED PROFESSOR YUAN-CHENG B. FUNG (1)

Chairs: Linhong Deng and Li Yang

S16-1 Morphogenesis and mechanobiology of airway smooth muscle cells on 3D tubular micropatterns as mechanism of bronchial airway development

Linhong Deng, Yang Jin, Mingzhi Luo, Lei Liu, Jingjing Li

S16-2 Glycosylation is a strong molecular determinant of MUC5AC rheology in airway mucus at both single protein and bulk solution levels

Lei Liu, Mingzhi Luo, Yan Pan, Jingjing Li, Linhong 
S16-3 Dynamics of neutrophil transmigration mediated by beta-2 integrin via $\mathrm{P}$ - and E-selectins

Yan Zhang, Mian Long

S16-5 Influence of different rhythms sound wave to serotonin concentration in rats hippocampus

Yang Ren, Zhidan Deng

S17: RHEOLOGY AND MICROCIRCULATION

Chairs: Lucas Prantl and Gerhard Pindur

S17-1 Longitudinal analysis of thrombin generation biomarkers in venous thromboembolism

Gerhard Pindur, Aida Beye, Bernhard Stephan, Harald Helling

S17-2 Comparison of PIRADS 3 lesions with histopathological findings after MRIultrasound fusion targeted biopsy of the prostate in a real-world setting Boris Schlenker, Maria Apfelbeck, Christian G. Stief, Dirk-Andre Clevert

S17-3 Does acoustic radiation force Elastography help to improve the diagnostic value of ultrasound in the preoperative characterization of tumors of the parotid gland? Pamela Zengel, Florian Notter, Dirk Andre Clevert

S17-4 Technologies for adipose stem cell isolation L. Prantl, V. Brebant, S. Klein, A. Anker, C Strauss, O. Felthaus

S17-5 Blood rheology in breast and gynecologic cancer patients at primary diagnosis and stage of cancer progression O. Schelkunov, P. Tsikouras, R. Csorba, W. Rath, G-F. von Tempelhoff

S17-6 First experiences with a clinical work-flow integrated CAM Assay in Patients with oral squamous cell carcinoma

P. Kauffmann, M. Troeltzsch, P. Brockmeyer, H. Bohnenberger, P. Stroebel, M. Manzke, R. Cordesmeyer, H. Schliephake, L. Prantl, T. Aung

S18: NANOSTRUCTURES IN DISEASE AND HEALTH

Chairs: Květoslava Burda and Marek Cyrklaff

S18-1 Malaria parasites, host-erythrocytes and blood circulation Marek Cyrklaff

S18-2 Polyhedrocytes in type 2 diabetes Grzegorz Gajos, Aleksander Siniarski, Joanna Natorska, Michat Zabczyk, Jakub Siudut, Aneta Undas

S18-3 Differentiation between various melanomas based on biophysical characterization of their properties

Justyna Bobrowska, Joanna Pabijan, Kamil Awsiuk, Jakub Rysz, Andrzej Budkowski, Matgorzata Lekka

S18-4 Endothelial nanomechanics in vascular diseases - an ex vivo AFM nanoindentation study

Marta Targosz-Korecka, Magdalena Jaglarz, Katarzyna Matek-Ziętek, Stefan Chtopicki, Marek Szymoński 
O6: RED BLOOD CELL AGGREGATION

Chairs: Dong-Guk Paeng and Norbert Nemeth

O6-1 Alterations in RBC aggregation during incubation in glucose solution Alicja Szotna-Chodór, Paulina Grychtal, Bronistaw Grzegorzewski

O6-2 Numerical study of red blood cell aggregation kinetics under sinusoidal pulsatile flow

Cheong-Ah Lee, Soohong Min, Minho Lee, Dong-Guk Paeng

O6-3 Structure and stability of red blood cell aggregates in model flows Thomas Podgorski, François Yaya, Gwennou Coupier, Daniel Flormann, Christian Wagner

O6-4 Covalent immobilization of biomolecules on stent materials through mussel adhesive protein coating to promote cell adhesion

Yi Wang, Hualin Lan, Tieying Yin, Yazhou Wang, Guixue Wang

O6-5 The changes of vascular mechanical properties of porcine coronary artery after stent implantation

Yinping Zhao, Lili Tan, Xiaojuan Zhang, Juhui Qiu, Guixue Wang

Thursday, July 5th

9.00-10.00 ISCH Plenary Lecture (L5)

Chair: Gerard Nash

Lecture: Sehyun Shin

Microfluidic platelet function assays

\subsection{0-12.00 Symposia S19-S23}

S19: INTERACTION OF BLOOD CELLS/TISSUE ENGINEERING

Chairs: Friedrich Jung and Anna Blocki

S19-1 Long-term prognosis of coronary microvascular dysfunction Remzi Anadol, Tommaso Gori

S19-2 AD-MSCs change their morphology and secretion profile as a response to changes in substrates' elastic properties in combination with inflammatory stimuli M. Papagrigorakes, N. Chirico, A. Blocki, A. Neffe, F. Jung, N. Ma, A. Lendlein

S19-3 Thrombogenicity testing of polymers: Round-robin study to assess inter-center variability

Steffen Braune, Claudia Sperling, Manfred F. Maitz, Ulrich Steinseifer, Johanna Clauser, Bernhard Hiebl, Stefanie Krajewski, Hans P. Wendel, Friedrich Jung

S19-4 The controversial origin of pericytes - implications for cell-based therapies Anna Blocki, Sebastian Beyer, Friedrich Jung, Michael Raghunath

S19-5 A facile way to achieve biomimetic laminin networks on substrates Thanga Bhuvanesh, Rainhard Machatschek, Burkhard Schulz, Yan Nie, Nan Ma, Andreas Lendlein

S19-6 Medical compression stockings reduce hypertension of nailfold capillaries at the toe of patients with chronic venous insufficiency 
Michael Jünger, Anja Oelert, Manuela Kittel, Hermann Haase, Martin Hahn

S20: FLOW VISUALIZATION OF CARDIOVASCULAR DEVICES

Chairs: Keefe Manning and Ajit Yoganathan

S20-1 Visualization of cardiac flows: In vitro, in vivo, and in silico studies Immanuel David Madukauwa-David, Vrishank Raghav, Prem A. Midha, Vahid Sadri, Phillip Trusty, Zhenglun Wei, Ajit Yoganathan

S20-3 Leveraging fluid dynamic measurements to improve cardiac device design Keefe Manning

S20-4 Hemodynamics assessment of new transcatheter bi-caval valves in the interventional treatment of tricuspid regurgitation Munirah Binte Ismail, Foad Kabinejadian, Yen Ngoc Nguyen, Hwa Liang Leo

S21: MACRO AND MICRORHEOLOGICAL BLOOD CHARACTERISTICS UNDER PHYSIOLOGICAL AND PATHOLOGICAL CONDITIONS

Chairs: Nadia Antonova and Eugene V. Roitman

S21-1 Analysis of the cutaneous blood flow responses and microvascular tone regulation in patients with type 2 diabetes mellitus. Relationship to rheological properties of blood

Nadia Antonova, Vasilka Paskova, Irena Velcheva, Nino Chaushev, Sergey Podtaev, Kirill Tsiberkin

S21-2 Relationship between rheological properties of blood and leukocyte adhesion under flow conditions in patients with type 2 diabetes mellitus

Anika Aleksandrova, Nadia Antonova, Alexei Muravyov, Ekaterina Uzikova

S21-3 Hemorheological disturbances as the thrombosis-developing factor

Eugene Roitman, Alla Shabalina, Marine Tanashyan, Irina Kolesnikova

S21-5 Local carotid stiffness in patients with cerebral small vessel disease. Relation to blood viscosity

Irena Velcheva, Nadia Antonova, Tsocho Kmetski, Galina Tsonevska, Anika Alexandrova

S22: THE GLYCOCALYX - ITS ROLE IN DISEASE

Chairs: John Tarbell and Hans Vink

S22-1 Role of the glycocalyx in atheroprotective vs. atheropermissive endothelium function

Eno Ebong, Ian Harding, Solomon Mensah, Ming Cheng, Ronodeep Mitra

S22-2 Loss of the retinal endothelial glycocalyx in diabetes

Norman R. Harris, Wendy Leskova, Haley Peace, Patsy R. Carter, Randa Eshaq

S22-3 Endothelial glycocalyx restoration by growth factors in diabetic kidney disease Karen Onions, Sara Desideri, Nicola Buckner, Monica Gamez, Gavin Welsh, Andrew Salmon, Simon Satchell, Rebecca Foster

S22-4 Modification of renal macrophage signalling via MCP-1 inhibition reduces albuminuria in diabetic nephropathy 
Bernard van den Berg, Margien Boels, Angela Koudijs,Cristina Avramut, Wendy Sol, Annemarie van Oeveren-Rietdijk, Hetty de Boer, Cees van Kooten, Dirk Eulberg, Johan Van der Vlag, Daphne IJpelaar, Ton Rabelink

S23: SPECIAL SYMPOSIUM TO CELEBRATE THE CENTENNIAL OF DISTINGUISHED PROFESSOR YUAN-CHENG B. FUNG (2)

Chairs: Linhong Deng and Li Yang

S23-1 Investigation on energy characteristic of red blood cell deformability: A quantitative analysis of extending and retracting curves based on Atomic Force Microscopy

Dong Chen, Xiang Wang

S23-3 Nitric oxide regulates human erythrocyte deformability through regulating band 3 phosphorylation status in hypoxia

Yajin Zhao, Xiang Wang

S23-4 Development history, progress and future prospects of biorheology and biomechanics in Chongqing University

Wang Guixue

S23-5 Zebrafish caudal vein formation is flow shear stress dependent Lin Wen

13.00-14.00 Fahraeus Gold Medal Award (L6)

Ceremony and Lecture

Laudatio: Nadia Antonova

Lecture: Carlota Saldanha

Multifunctional life of the erythrocyte

14.15-15.45 Symposia S24-S26/Free Communications O7-08

\section{S24: CLINICAL STUDIES IN HEMORHEOLOGY}

Chairs: Byoung K. Lee and KyuChang Won

S24-1 The role of hemorheologic changes in diabetic microvascular complications Jun Sung Moon, Kyu Chang

S24-2 RBC abnormalities presented with clinical diagnostic variables in sepsis Choon Hak Lim, Jung Min Youn, Eun Gi Ko

S24-3 Decrease myocardial perfusion associated with hemorheologic parameters in patients with type 2 Diabetes

Byoung Kwon Lee, Minhee Cho, Sehyun Shin

S24-4 Erythrocyte aggregation and deformability as factors determining capillary blood flow in patients with arterial hypertension Andrei Lugovtsov, Alexey Semenov, Yuri Gurfinkel, Petr Ermolinskiy, Anastasiya Maslyanitsina, Nikita Povalyaev, Larisa Dyachuk, Elena Pavlikova, Alexander Priezzhev 
S25: CLINICAL MICROCIRCULATION

Chairs: Dirk Andre Clevert and Isabel Wiesinger

S25-1 Postoperative control of vascularized lymph node transfer (VLNT) for the treatment of extremity lymphedema: Ultrasound guided lymph node monitoring using contrast enhanced ultrasound (CEUS)

T. Aung, C. Taeger, S. Geis, A. Kehrer, L. Prantl, E.M. Jung

S25-2 The Use of Indocyanine green (ICG) imaging technique in the groin lymphocele microsurgical resection

M. Ranieri, C.D. Taeger, S. Geis, S. Klein, P. Lamby, D. Schiltz, K. Pfister, L. Prantl, V. Hoesl, T. Aung

S25-3 Significance of high-resolution Color-Duplex-Ultrasound (CDU) designing adipocutaneous, fasciocutaneous and chimeric perforator flaps

A. Kehrer, S. Geis, C. Taeger, N. Platz Batista da Silva, E.M. Jung, L. Prantl, V. Mandlik

S25-4 Influence of systemic vasopressor drugs and fluid administration on microcirculation in free tissue transfer

A. M. Anker, L. Prantl, C. Strauss, V. Brébant, S. M. Klein

S25-5 ICG-fluorescence-angiography-a new indication in revascularized digits and toes C. Strauss, A. Anker, L. Prantl, N. Heine, C. Wenzel, S. Geis, T. Aung, V. Brébant

S25-6 ICG-fluorescence-angiography in revascularized digits - first results of a standardized clinical study

C. Strauss, A. Anker, V. Brébant, L. Prantl, D. Schiltz, R. Kemper, S. Geis, T. Aung Regensburg, Germany

S26: RED BLOOD CELL NITRIC OXIDE/RHEOLOGY

Chairs: Michael Simmonds and Philippe Connes

S26-1 Nitric oxide synthase activity at various levels and durations of shear stress

Michael Simmonds

S26-2 Erythrocyte nitric oxide dependent of acetylcholinesterase receptor

Carlota Saldanha, Ana Silva-Herdade

S26-3 Hydroxyurea therapy modulates sickle cell anemia red blood cell physiology by acting as a nitric oxide donor: Impact on RBC deformability, oxidative stress and nitric oxide synthase activity

Elie Nader, Marijke Grau, Romain Fort, Nicolas Guillot, Cyril Martin, Giovanna Cannas, Solène Poutrel, Arnaud Hot, Alexandra Gauthier, Wilhelm Bloch, Marc Romana, Philippe Connes

S26-4 The multifaceted role of nitrite and the epigenetic nitric oxide donor, RRx-001 on erythrocyte deformability

Selma Cirrı, Özlem Yalcin

07: DISEASE AND HEMORHEOLOGY

Chairs: Gerard Nash and Sajad Ahmadizad 
07-1 Do changes in bone marrow pressure contribute to the egress of cells (RBC, reticul.) from bone marrow?

Zbigniew Dabrowski, Anna Marchewka, Aneta Teległów, Maria Fornal

07-2 Platelet-derived extracellular vesicles promote the adhesion of flowing neutrophils to endothelial cells

Sahithi Kuravi, Paul Harrison, G.Ed Rainger, Gerard Nash

07-3 Morphological and metabolic abnormalities of erythrocytes as risk factors for Alzheimer's Disease

Francesco Misiti, Marco Girasole, Simone Dinarelli

07-4 Effects of two different high intensity interval training protocols on hemorheological variables in hypertensive patients

Sajad Ahmadizad, Mohammad Soltani, Neda Aghaei Bahmanbeglou

07-5 Sedentarity status as a regulator of the optimal hematocrit: Involvement of red cell deformability?

Jean-Frederic Brun, Emmanuelle Varlet-Marie, Bénédicte Marion, Céline Roques, Marlène Richou, Eric Raynaud de Mauverger

07-6 The effects of n-6 polyunsaturated free fatty acids dietary intake on hemorheology and endothelium-dependent microvascular function Ines Drenjančević

O8: BIORHEOLOGY AND BIOTECHNOLOGY-1

Chair: Guixue Wang

O8-1 Fabrication of gradient nanofibrous scaffold for interface tissue engineering Li Yang, Peixing Chen, Yu Zhang

O8-2 Tanshinone can inhibit inflammation and angiogenesis in several chondrocytic cells

Li Yang, Yu Zhang, Peixing Chen

O8-3 The preliminary research of mechanical compress damage on neurons induced by hematoma

Wei Wang, Yin Yin, Jun Wang, Tieying Yin, Yazhou Wang, Guixue Wang

O8-4 Hemodynamic analysis of cerebral aneurysms: Suggestions for surgical options Shicheng He

Friday, July 6th

9.00-10.00 Plenary Lectures in Tribute to Prof. Oguz Baskurt (L7)

Chair: Jean-Frédéric Brun

Özlem Yalçın

Blood rheology as a determinant of blood flow: Physiological and clinical aspects Jon Detterich

Red blood cell rheology and nitric oxide production: A scientist on the forefront

10.30-12.00 Symposia S27-S29/Free Communications O9

S27: CELL MECHANICS AND CELL MECHANOBIOLOGY - 2 
Chairs: Toshiro Ohashi and Susumu Kudo

S27-1 Effect of local tensile stress field on bone matrix and cell alignment: An in vitro study

Taiji Adachi, Kei-ichi Ishikawa, Junko Sunaga, and Yoshitaka Kameo

S27-2 Blood vessel on a chip - 3D vs. 2D

Yukiko Matsunaga

S27-3 Mechanotargeting of nanoparticles to atherogenic endothelium

Pouria Fattahi, Sulin Zhang, Justin Brown, Yin-Ting Yeh, Peter Butler

S27-4 The roles of vessel pulsation and dilation in clearing extracellular waste from the brain

Ravi Kedarasetti, Bruce Gluckman, Patrick Drew, Francesco Costanzo

S28: RHEOLOGY AND MICROSTRUCTURE OF CELLULAR BLOOD FLOW

Chairs: Masako Sugihara-Seki and Ken-ichi Tsubota

S28-1 Effect of internal viscosity on suspension rheology of red blood cells

Naoki Takeishi, Marco Rosti, Yohsuke Imai, Shigeo Wada, Luca Brandt

S28-2 Hemolytic behavior of human red blood cells caused by osmotic pressure difference - Visualization of hemoglobin behavior by use of light absorption characteristics

Ryoko Otomo, Akihito Morita, Kiyoshi Bando

S28-3 Effects of red blood cells on blood flow in micro vessel network: In vitro experiment and computer simulation

Ken-ichi Tsubota, Yuya Kodama, Ryoma Kanai

S28-4 Capillary flow imaging with genetically-engineered red blood cells in the living animal brain

Yuika Kurihara, Takuma Sugashi, Kazuto Masamoto

S28-5 Fluid dynamical study of preferential distributions of blood cell components in microchannel flows

Masako Sugihara-Seki, Nozomi Takinouchi, Tenki Onozawa, Junji Seki

S29: ROLE OF GASOTRANSMITTERS (NO, CO AND $\mathrm{H}_{2}$ S) IN BLOOD CELL FUNCTIONS AND THE MOLECULAR MECHANISMS OF THEIR MICRORHEOLOGY ALTERATIONS

Chairs: Carlota Saldanha and Eugene Roitman

S29-1 Leukocytes as a link between inflammation and erythrocyte nitric oxide Ana Silva-Herdade, Carlota Saldanha

S29-2 Contribution of fibrinogen to erythrocyte scavenger nitric oxide Carlota Saldanha

S29-3 Role of nitrogen oxide and hydrogen sulfide as signaling molecules in the change of red blood cell microrheology in patients with type 2 diabetes mellitus Svetlana Bulaeva, Alexei Muravyov, Irina Tikhomirova, Pavel Avdonin

S29-4 Change of microrheological characteristics of erythrocytes under the influence of donors of gasotransmitters $\mathrm{NO}$ and $\mathrm{H} \mathrm{S}$ : In vitro study 
Yulia Malysheva, Alexei Muravyov

\section{O9: BIORHEOLOGY AND BIOTECHNOLOGY-2}

Chair: Jinxuan Wang

O9-1 Proteomic analysis of ApoE-/- mice with disturbed flow model

Li Tianhan, Wang Guixue

O9-2 Effects of suspension state on the biological behavior of breast cancer cells

Yonggang Lv, Xiaomei Zhang, Ying Zhang, Ya Wang

O9-3 Preliminary study of endothelial cell tight junction protein in response to different mechanical stimuli

Yazhou Wang, Desha Luo, Tieying Yin, Guixue Wang

O9-4 PI3K-nos2b signaling is crucial for simulated microgravity-mediated angiogenesis in zebrafish CVP network

Daoxi Lei, Guixue Wang

09-5 Ferric iron, lipopolysaccharide and lipoteichoic acids can induce anomalous fibrin amyloid formation: An assessment with novel Amytracker ${ }^{\mathrm{TM}}$ stains and thioflavin $\mathrm{T}$

Martin Page, Douglas Kell, Etheresia Pretorius

\subsection{0-14.30 Symposia S30-S32}

S30: FROM RHEOLOGY TO MICROCIRCULATION: NEW INSIGHTS Chairs: Gregorio Caimi and Antonio Colantuoni

S30-1 Red blood cell rheology under different pathological conditions Patrizia Caprari, Carlotta Bozzi, Sara Massimi, Loretta Diana

S30-2 Role of hemorheological alterations in skin ulcers Rosalia Lo Presti, Patrizia Caprari, Gregorio Caimi

S30-3 Hemorheology in kidney disease Francesco Fontana

S30-4 Rat pial microvascular changes during brain hypoperfusion and reperfusion injury: Role of antioxidant substances

Martina Di Maro, Martina Chiurazzi, Dominga Lapi, Teresa Mastantuono, Laura Battiloro, Gilda Nasti, Antonio Colantuoni

S30-5 Bridging the gap from basic microcirculation to the clinical world Romeo Martini, Antonio Colantuoni

S31: CARDIOVASCULAR BIOMECHANICS FROM CELLS TO ORGANS Chairs: Noriyuki Kataoka and Ryoko Otomo

S31-1 Biorheology of bile Minh Nguyen Ngoc, Hiromichi Obara, Kenji Shimokasa, Junfang Zhu

S31-2 Electrical impedance spectroscopic technique for cancerous cell sensing by considering the extracellular fluid around cells 
Daisuke Kawashima, Songshi Li, Michiko Sugawara, Hiromichi Obara, Masahiro Takei

S31-3 Matrix metalloprotease production of vascular endothelial cells under extremely high wall shear stress condition

Naoya Sakamoto, Yuki Oyama, Yuta Horie, Masanori Nakamura, Naoyuki Kimura

S31-4 Observation of microscopic elastic structure in arterial tissue by use of a scanning haptic microscope (SHM)

Takeshi Moriwaki, Sadao Omata, Yasuhide Nakayama

S31-5 Ultrafast imaging of cell elasticity with optical microelastography

Guy Cloutier, Grasland-Mongrain, Ali Zorgani, Shoma Nakagawa, Simon Bernard, Lia Gomes Paim, Greg FitzHarris, Stefan Catheline

S32: COMPUTATIONAL MODELS OF THROMBOSIS C

Chairs: Keefe Manning and Shawn Shadden

S32-1 The contact activation system in device-related thrombosis modeling Rodrigo Méndez Rojano, Simon Mendez, Franck Nicoud

S32-2 Development of a device-induced computational thrombosis model Keefe Manning

S32-3 Reduced-order computational modeling of thrombogenic potential in large arteries

Kirk Hansen, Shawn Shadden

\section{POSTERS (P1-P36)}

P1 Effects of hypertrophy and strength weight training on resting levels and responses of hemorheological parameters to a single session of exercise Fatholah Havil, Afshar Jafaria, Sajad Ahmadizad, Saeed Nikoukheslat

P2 Modulation of erythrocyte mechanical function by calcium-calmodulin-protein kinase $\mathrm{C}$

Ali Cenk AKSU, Yasemin AKSU, Dilan ATAR, Zeynep Busra Kısakurek, Elif Ugurel, Özlem Yalcin

P3 Clinical relevance of hemodynamic viscosity measurement in vascular study Tilly Alexandre

P4 Analysis of seismocardiographic signals by the discrete Chebyshev transform Mikhail Basarab, Natalya Konnova

P5 Fetal growth retardation and oxygen delivery hemorheological predictors in hypertensive vs normotensive pregnant women

Jean-Frédéric Brun, Emmanuelle Varlet-Marie, Pierre Boulot, Bénédicte Marion, Céline Roques, Eric Raynaud de Mauverger

P6 Leg electrical resistance predicts venous blood viscosity and hematocrit Emmanuelle Varlet-Marie, Laurent Vachoud, Bénédicte Marion, Céline Roques, Marlène Richou, Eric Raynaud de Mauverger, Jean-Frédéric Brun

P7 The transient hyperviscosity syndrome of labor and delivery shifts the hemorheological profile toward a lower ability to deliver oxygen to tissues 
Jean-Frédéric Brun, Pierre Boulot, Emmanuelle Varlet-Marie, Bénédicte Marion, Céline Roques, Eric Raynaud de Mauverger

P8 Studies of the chemically induced changes of the mechanical properties of murine RBCs with the use of Atomic Force Microscopy (AFM)

Katarzyna Bulat, Jakub Dybas, Aneta Blat, Mateusz Mardyla, Anna Rygula, Stefan Chłopicki, Małgorzata Baranska, Katarzyna M. Marzec

P9 Investigation on energy characteristic of red blood cell deformability: A quantitative analysis of extending and retracting curves based on atomic force microscopy Dong Chen, Xiang Wang

P10 Measurement of glycocalyx volume: An unreliable biomarker FitzRoy Curry, Charles Michel

P12 Resonance Raman spectroscopy in detection and differentiation of various hemoglobin derivatives inside packed human red blood cells

Jakub Dybas, Malgorzata Baranska, Stefan Chlopicki, Katarzyna M. Marzec

P13 Effects of different rehabilitation models on the elongation index of erythrocytes, study of activity of chosen erythrocyte enzymes, and the level of glutathione in elderly women

Katarzyna Filar-Mierzwa, Anna Marchewka, Zbigniew Dabrowski, Paulina Aleksander-Szymanowicz

P14 Effects of whole body vibration training on hemorheological blood indicators in young healthy women

Halina Gattner, Justyna Adamiak, Magdalena Kepińska, Anna Piotrowska, Olga Czerwińska-Ledwig, Sylwia Mętel, Wanda Pilch

P15 Evaluation of vascular effects of photodynamic therapy in skin microcirculation using different photosensitizers

Tatyana Grishacheva, Dinara Faizullina, Nickolay Petrishchev, Irina Mikhailova

P16 Analysis of flow and thrombus development within PDMS channels of varying geometry

Tice Harkins, Jeremey Myslowski, Keefe Manning

P17 Measurement of blood viscosity by measuring flows in microfluidic channel Hyeonji Hong, Eunseop Yeom

P18 Repeated whole body cryotherapy treatments does not cause changes in hemorheological parameters in healthy people

Magdalena Kepińska, Zbigniew Szyguła, Zbigniew Dabrowski

P20 Cell volume regulation via the calcium-activated potassium channel KCa3.1 contributes to red blood cell compliance under shear

Jan Lennart Kuck, Michael J. Simmonds

P21 Effects of rowing on rheological properties of blood

Mateusz Mardyła, Aneta Teległów, Zbigniew Dąbrowski, Jakub Marchewka, Jacek Gtodzik, Barttomiej Ptaszek

P22 Impaired deformability of erythrocytes in hypertensive rats and patients: Investigation by nickel mesh filtration technique

Toru Maruyama, Keita Odashiro, Takehiko Fujino, Shiro Mawatari

P23 Determinants of sublethal trauma to red blood cells: Effects of shear rate at standardized shear stresses 
Jacob Turner, Antony McNamee, Jarod Horobin, Lennart Kuck, Kieran Richardson, Michael Simmonds

P24 Susceptibility to mechanical damage of density-fractionated red blood cells Antony McNamee, Kieran Richardson, Lennart Kuck, Kai Robertson, Michael Simmonds

P25 Clinical evaluation of laser Doppler flowmetry for diagnosis of microcirculatory disorders

Christof Mrowietz, R.P. Franke, G. Pindur, R. Sternitzky, F. Jung, U. Wolf

P26 Erythrocytes aggregation index correlate with oxidative stress and hydrogen sulfide plasma concentration in diabetes mellitus

Agata Pietrzycka, Katarzyna Krzanowska, Przemysław Miarka, Władysław Sułowicz, Marcin Krzanowski

P27 Effects of carboxylated multiwall carbon nanotubes on erythrocytes stability and functionality

Mateusz Przetocki, Józef Korecki, Grzegorz Gajos, Leszek Stobiński, Krzysztof Matlak, Kvetoslava Burda

P28 Influence of different rhythms sound wave to serotonin concentration in rats hippocampus

Yang Ren, Zhidan Deng, Xiang Wang

P29 Physical properties of erythrocytes improve in hemochromatosis patients with repeated venesection therapy

Kieran Richardson, Antony McNamee, Michael Simmonds

P30 Experimental characterization of the embolus trapping efficiency of the U.S. FDA generic inferior vena cava filter

Joshua Riley, Nicole Price, Brent Craven, Kenneth Aycock, Keefe Manning

P31 Effects of pentoxifylline on hemodynamic and hemorheological parameters in SHRs during arterial hypertension development

Alexander Shamanaev, Oleg Aliev, Anastasia Sidekhmenova, Anna Anischenko, Mark Plotnikov

P32 Effect of cholesterol-rich diet on hematological and hemorheological parameters in rabbits

Bence Tanczos, Viktoria Somogyi, Mariann Bombicz, Bela Juhasz, Norbert Nemeth, Adam Deak

P33 Changes in biochemical properties of the blood in winter swimmers Aneta Teległów, Jakub Marchewka, Anna Marchewka, Zbigniew Dąbrowski, Barttomiej Ptaszek, Mateusz Mardyta

P34 The paraclinical evolution in diabetic hypertensive patients with increased abdominal circumference

Cornel Cezar Tudorica, Ana Maria Vintila, Stefan Dragos Tudorica, Mirela Gherghe

P35 Alterations of red blood cell deformability and mechanical stability by heattreatment on animal blood samples

Gabor Varga, Adam Attila Matrai, Balazs Szabo, Viktoria Somogyi, Barbara Barath, Bence Tanczos, Norbert Nemeth

P36 Shear-dependency of the predicted ideal hematocrit 
Emmanuelle Varlet-Marie, Laurent Vachoud, Bénédicte Marion, Céline Roques, Marlène Richou, Eric Raynaud de Mauverger, Jean-Frédéric Brun 